\title{
Deploying Biomolecules as Anti-COVID-19 Agents
}

\author{
Sanjay K. S. Patel ${ }^{1} \cdot$ Jung-Kul Lee $^{1} \cdot$ Vipin C. Kalia $^{1}$
}

Received: 8 May 2020/Accepted: 30 May 2020/Published online: 9 June 2020

(C) Association of Microbiologists of India 2020

\begin{abstract}
Severe acute respiratory syndrome coronavirus (SARS-CoV-2) known as COVID-19 has emerged as a major threat to human existence. COVID-19 seems to have undergone adaptive evolution through an intermediate host, most likely bats. The flu leads to severe pneumonia that causes respiratory and multi-organ failure. The absence of any known treatment procedures, drugs, or vaccines has created panic around the World. The need is to develop rapid testing kits, drugs and vaccines. However, these proposals are time-consuming processes. At present social distancing along with previously known traditional medicines can act as quick and short-term alternatives for treating this viral flu.
\end{abstract}

Keywords Bat - Corona virus · Disease - Human .

Transmission

\section{Introduction}

Biologists have revealed that the populations of more than $30 \%$ of all vertebrates have been declining during the last few centuries. It has been realized that there is a need to curb the basic drivers for these immense losses. There have been cases of Catarina pupfish going extinct without making news headlines. Christmas Island pipistrelle, a vesper bat vanished without a whisper. Human races have

Jung-Kul Lee

jkrhee@konkuk.ac.kr

$\triangle$ Vipin C. Kalia

vckaliaku@gmail.com

1 Department of Chemical Engineering, Konkuk University, Seoul 05029, Republic of Korea been under threat of "extinction" having seen some of the worst pandemic disasters. Human Immunodeficiency Virus infection and Acquired Immune Deficiency Syndrome (HIV/AIDS) has taken around 36 million human lives during the last four decades. Even at present, more than 30 million people are living with HIV. Constant efforts to find treatments and generating awareness has helped to decline the death rate due to HIV/AIDS from 2.2 million to 1.6 million (https://www.mphonline.org/worst-pandemicsin-history/). The flu pandemic of 1968 caused due to Influenza A virus spread from Hong Kong to Vietnam, India, The Philippines, Singapore, Europe, the United States, and Australia, with less than 3 weeks of its first report. Despite a low mortality rate of $5 \%$, it resulted in killing 1 million people, of which 50\% were residents of Hong Kong. From 1956 to 1958, Asian flu caused by Influenza A (subtype H2N2) with its origin in China caused 2 million deaths in China, Hong Kong, Singapore, and the United States (https://www.mphonline.org/worst-pan demics-in-history/). Among the worst pandemics recorded during the twentieth century was the flu of 1918-1920, which infected around $33 \%$ of the world's population resulting in a death toll of 20-50 million people, equal to a mortality rate of $10-20 \%$. The most disturbing aspect was that it struck even healthy young adults. Prior to that, between 1910 and 1911, cholera pandemic with its origin in India was spread to Russia, Eastern Europe, North Africa, and the Middle East. It had taken the lives of more than 0.8 million people with more than $90 \%$ being from India alone (https://www.who.int/). In the nineteenth century, influenza and cholera have been striking a human being quite frequently causing millions of deaths (https:// www.who.int/). The emergence of a novel severe acute respiratory syndrome coronavirus (SARS-CoV-2, renamed as COVID-19) in 2019 from Wuhan, China has led to a 
global crisis and it has been declared as a pandemic emergency by World Health Organization (WHO) due to its fast rate of transmission among human beings [1, 2]. SARS-CoV-2 exhibits unique spiked protein (S glycoprotein) and belongs to the family of Coronaviridae [3]. About 27,000 viral genomic sequences are available via the Global Initiative on Sharing All Influenza Data (https:// www.gisaid.org/). SARS-CoV-2 enters the host cell by attaching $\mathrm{S}$ glycoproteins to angiotensin-converting enzyme 2 (ACE2) that is mediated via serine protease TMPRSS211 [3]. The possible candidate drugs have been based on (1) inhibition of binding ACE2 to SARS-CoV-2 via inhibition of the ACE2 and TMPRSS211, (2) polyclonal antibody against $\mathrm{S}$ glycoproteins, and (3) inhibition of replication [3, 4]. Non-availability of any treatment procedures, drugs, or vaccines has created panic around the World. In this review, we have described the present scenario on COVID-19 and discussed the use of traditional medicines-based biomolecules in its mitigation.

\section{COVID-19}

COVID-19 (previously labelled as 2019-nCoV) is the main causative organism responsible for acute pneumonia. Coronaviruses (CoVs) are a group of genetically distinct viruses, which originated from broad ranges of hosts, including animal and bird species, and primarily cause respiratory and intestinal infections to humans and animals [1, 5-8]. In 2002-2003, CoVs surfaced as a severe acute respiratory syndrome (SARS) with cases of 'atypical pneumonia' in China and Hong Kong [9]. SARS originating from bats caused a major threat to humans through interspecies transmission through another host such as raccoon dogs or Himalayan palm civets. It led to around 8000 infections in 26 countries and a high fatality rate of 10\%. In 2012, CoVs of animal origin-known as Middle East respiratory syndrome coronavirus (MERS) emerged with rarely transmitting history between humans [9]. It had a much higher fatality rate up to $34.4 \%$ globally till November 2019. These infections posed a severe public health risk and caused substantial damage to the economy of those e affected. For genetically heterogeneous SARSlike CoVs (Alphacoronavirus and Betacoronavirus) bats seems to be the natural reservoirs, in different parts of China. These CoVs are well-known for their emergence from natural hosts [7,9]. Transmission of COVID-19 possibly involved an adaptive evolution through an intermediate host (bat) before infecting humans. Although the exact mechanism of transmission of COVID-19 to humans is yet to be elucidated. -However, the primary evidence to support this route is the genomic identity of up to $96 \%$ nucleotides with a bat (BetaCoV/RaTG13/2013) [7]. The phylogenic comparison has also pointed out towards convergent evolution or multiple recombination events, between the two virus strains of diverse evolutionary origins. The major determining factor of the cell tropism is the spike protein, leading to the transmission of CoVs among different species [3, 7]. In fact, the virus is bound to the cellular receptor through this protein, which in turn catalyzes its entry by membrane fusion. Although, no antiviral agents are known to act against this virus, however, monoclonal antibodies and convalescent sera are known to inhibit MERS or SARS in model systems. However, these sera and antibodies may not prove very effective in handling the present outbreak [7].

\section{Symptoms, Phases and Mortality}

In the recent outbreak of COVID-19, with possible transmission from bats, initially had shown pneumonia-like symptoms with unspecified etiology [10]. COVID-19 infected person showed flu-like symptoms with fever, cough, headache, muscular soreness, and dyspnea with an incubation period of about 2-24 days [1, 5, 7]. In a few cases, patients exhibited atypical symptoms, including vomiting and diarrhea. The epidemiology curve of COVID-19 broadly has been classified in different phases: (1) the start of the outbreak through exposure at a market (December 2019) to new cases (41 confirmed) beyond Wuhan, China (January 13, 2020) between humans transmission occurrence by close contact, (2) a rapid increase in confirmed cases by spreading of the virus within hospitals and family transmission outside China, which was nearly 20-folds than phase first till January 23, 2020 [7]. This resulted in the traditional mass movement of people (about 5 million people), which has contributed significantly in spreading of confirmed cases of COVID-19, and (3) finally, a cluster of cases marked on January 26, 2020 was the beginning of the third phase. The global COVID-19 mortality rate of $3.4 \%$ has been reported by WHO [7] (Tables 1,2)

\section{Screening and Testing}

CoVs are viruses with single stranded RNA genome sizes between 26 to $32 \mathrm{~kb}$ [11]. Initially, the screening of COVID-19 infection has done through measurements of temperature and related symptoms. The laboratory testing for COVID-19 detection includes methods based on the presence of the virus and the measurement of antibodies (serology) produced in response to infection [11]. The virus was confirmed using:-(1) PCR based reverse transcription (RT)-PCR detects CoVs specific RNA from either nasopharyngeal and throat swabs or sputum samples within a few hours to 2 days, and (2) high throughput nucleic acid sequencing, (3) non-PCR based technique of isothermal 
Table 1 Characteristic features of COVID-19

\begin{tabular}{ll}
\hline Characteristics & Description \\
\hline Origin & Bats (Wuhan, China) \\
Clinical symptoms & Flu-like symptoms - fever, cough, headache, and shortness in breathing \\
Time of incubation & $2-24$ days $(5.2$ days on average) \\
Genome (size) & Single stranded RNA $(\sim 28.8 \mathrm{kbp})$ \\
Genomic similarity & $96 \%($ BetaCoV/RaTG13/2013), $77.5 \%(\mathrm{SARS}-\mathrm{CoV})$ and $50.0 \%(\mathrm{MERS}-\mathrm{CoV})$ \\
Global infections (deaths) $^{\mathrm{a}}$ & $5,821,077(358,104)$ infections over 213 countries and territories \\
Mortality rate & $6.1 \%$ \\
Disease conditions & Respiratory system failure, septic shock, and multiple organs failure
\end{tabular}

as on 28th May 2020

Table 2 Biomolecules as potential anti-COVID-19 agents

\begin{tabular}{|c|c|c|c|}
\hline Description & Herbs/herbal medicine formulation & $\begin{array}{l}\text { Course } \\
\text { time/mode }\end{array}$ & Reference \\
\hline \multirow[t]{6}{*}{ Herbs } & $\begin{array}{l}\text { Chrysanthemi flos, Forsythiae fructus, Farfarae flos, Liquorice, Lonicerae japonicae flos, } \\
\text { Mori cortex, Mori follum, Peucedani radix and Rhizoma fagopyri cymose }\end{array}$ & Full treatment & [19] \\
\hline & Erigeron breviscapus, Radix bupleuri and Tamaricis cacumen & Early stage & \\
\hline & Coptidis rhizome, Houttuyniae herba, Hoveniae dulcis semen and Inulae flos & Middle stage & \\
\hline & $\begin{array}{l}\text { Ardisiae japonicae herba, Asteris radix et rhizome, Eriobotryae folium, Euphorbiae } \\
\text { helioscopiae herba, Ginkgo semen, Hedysarum multijugum maxim and Lepidii semen } \\
\text { descurainiae semen }\end{array}$ & $\begin{array}{l}\text { Middle and later } \\
\text { stages }\end{array}$ & \\
\hline & Anemarrhenae rhizome and Epimrdii herba & Later stage & \\
\hline & Fortunes bossfern rhizome & $\begin{array}{l}\text { Initial } \\
\text { prevention }\end{array}$ & \\
\hline \multirow{3}{*}{$\begin{array}{l}\text { Traditional } \\
\text { Chinese } \\
\text { medicines }\end{array}$} & Re Du Ning, Shen Fu, Shen Qi Fu Zheng, Tan Re Qing, Xi Yan Ping and Xue Bi Jing & Injection & [17] \\
\hline & $\begin{array}{l}\text { Gu Biao Jie Du Ling, Jin Yin Hua Tang, Jing Yin, Kang Bing Du, Ke Qing, Lian Hua Qing } \\
\text { Wen and Tan Re Qing }\end{array}$ & Capsule/granules & \\
\hline & Ke Su Ting and Shuang Huang Lian & Oral liquid/syrup & \\
\hline
\end{tabular}

nucleic acid amplification has a testing period of $5 \mathrm{~min}$ [11-13]. Similarly, chest CT scans and radiographs to detect it were not found to be accurate for COVID-19 confirmation at early stages [11]. The antibody test targets the production of antibodies such as $\operatorname{IgA}, \operatorname{IgM}$, and $\operatorname{IgG}$ in response to COVID-19 infection in blood samples, which takes around 14 days after infection or needs to wait for the onset of symptoms. The procedure, however, takes only $15 \mathrm{~min}$ to detect the infection. Various approaches are under investigation for developing a rapid and low-cost detection kit with high specificity and selectivity for COVID-19 [11-13].

\section{Potential Transmission Between Hosts}

The infections of COVID-19 are not selective to any age group, such that even newborn infants have been among the confirmed cases. CoVs genomes exhibit high genomic plasticity enabling it to possess high recombination capacities [7]. These features have led to a high probability of adaptive mutations for utilizing multiple cellular receptors for efficient binding and entry by spike proteins into various hosts. This ability of CoVs may assume an alarming tendency to expand to wider host-species. Since, multiple species of CoVs are present in wildlife animals, who constantly interact among themselves, their expansion or transmission to humans is inevitable. This feature evidenced by the transmission of COVID-19 from humans to dogs, cats, and even tigers. Thus, surveillance is expected to prevent the virus from establishing in other hosts, which live in the vicinity of human beings [14, 15].

\section{Mitigation via Social Distancing}

COVID-19 has exhibited a much higher infection than SARS or MERS cases. Initially, to minimize the global spread after cases in China various approaches such as airport screening and traveling restrictions were largely 
implemented in a few countries [1, 16]. Due to the asymptomatic behavior of COVID-19 such as a longer incubation period suggested that quick tracking of the infected person is essential for limiting the human-to-human transmissions. The initial quaternity period of about 14 days for travelers was considered desirable [16]. But, even longer periods for incubations were required for visualizing of symptoms made the realization that it was a more critical scenario for its spread. The minimization of social interaction by limiting activities at workplaces, education centers public functions were suggested to be more effective in reducing the rapid spreading of infection $[1,2,16]$. Early enough, it was observed that age groups and the frequency of physical interaction may be influenced by geographical locations. Computational analysis of the data generated from measures of social distancing at the workplace, educational institutes, and lock-down suggested that either a 21 days lockdown or periodic shutdowns of 21 and 28 days, may prove effective to counter the COVID19 infection in countries like India. Alternatively, periodic two lockdowns of 3-4 weeks followed by a shorter lock-down with a gap of 5 days, or a long-term lock-down of 7 weeks may help to minimize the transmission of this infection among human beings [16]. These four approaches are likely to yield different -mortality cases with a maximum of 2727 , in the first strategy followed by 11,8 , and 6 in the later three approaches [16]. It thus implied that social distancing along with lock-down can counter COVID infection in any part of the world, including India, where medical facilities are limited.

\section{Conventional Treatments}

At present, no vaccines or drugs are available for specifically targeting this rapidly spreading disease. The most common practices are supportive care in combination with certain previously known but non-specific drugs. These seem to be the only options, at present. The strategy being envisaged right now is to take advantage of the similarities in the following features -epidemiological, genomic, and pathogenetic - of the SARS-CoV and SARS-CoV-2. Conventionally SARS-CoV-2 infection are treated using a combination of therapeutic agents: (1) ventilation for oxygen supply, (2) combinations of antibiotics amoxicillin, azithromycin, and fluoroquinolones, (3) antivirals such as chloroquine, favipiravir (T-705), interferon, lopinavir/ritonavir, oseltamivir, remdesivir, and ribavirin, (4) corticosteroids, and (5) convalescent plasma [17]. Among these various possibilities, remdesivir may prove to be an effective drug for handling COVID-19, as it has been already shown to be helpful in treating RNA viruses such as MERS and SARS $[18,19]$. Certain methods like antibody and plasma therapy through the donation of plasma by COVID-19 patients had been adapted in the cases of CoVs such as MERS and SARS. Other possibilities are using the neutralizing potential of monoclonal antibodies [11]. Melatonin has been suggested as a potent drug for this treatment [20]. Ivermectin seems to have the potential to inhibit COVID-19 in vitro [21]. Few pharmaceutical drugs, including HIV drugs and stem cells are under clinical trials, however, there are still major challenges to be handled [11, 20-25]. InVivo Biosystem has developed ACE2 humanized genetic models using Caenorhabditis elegans for COVID-19 research (https://tgx.elegans@invivobiosys tems.com).

\section{Traditional Medicines}

In the absence of the availability of specific anti-viral drugs or vaccines, a few Asian countries such as China, Thailand, and India have been relying on the use of traditional medicines. This expertise gained over at least a few centuries can have a short-term effect on COVID-19. Almost 85\% of COVID-19 patients in China are treated using traditional medicines such as herbal formulations Yu Ping Feng San and Sang Ju Yin, which modulate the T-cells and enhance host defense mechanisms [17, 26]. A few other combinations of traditional medicines such as Lian Hua Qing Wen Capsule, Shuang Huang Lian, and Ma Xin Gan Shi Tang can be expected to be effective as therapeutics against viral infections [17, 27, 28]. Many traditional herbal extracts and compounds have shown potential activity against $\mathrm{CoV}$, these include: (1) root extract of Isatis indigotica, Chinese Rhubarb extract, flavonoids (Epigallocatechin gallate, herbacetin, litchi seeds extract, pectolinarin, rhoifolin, quercetin, and gallocatechin gallate), and extract of Houttuynia cordata inhibit SARS-3CLpro enzyme, (2) Scutellarein and myricetin inhibit non-structural protein (nsP13) activity, (3) Glycyrrhizin from Glycyrrhizae radix inhibits viral adsorption and penetration, (4) 3- $\beta$-D-glucoside, herbacetin, helichrysetin isobavaschalcone, and quercetin inhibit MERS-3CLpro enzyme, (5) cepharanthine, fangchinoline, and tetrandrine, inhibit the expression of proteins such as nucleocapsid and HCoV-OC43 spike, (6) TSL-1 and quercetin from Toona sinensis Roem prevent the invasion of SARS into cells, (7) Emodin obtained from Polygonum and Rheum inhibit interactions of virus with angiotensin-converting enzyme (ACE), (8) derivatives of Kaempferol inhibit 3a channels, (9) Baicalin obtained from Scutellaria baicalensis inhibits ACE, Saikosaponins eliminate viral penetration and early stage CoVs infection, and (10) luteolin extracted from Veronicalina riifolia and tetra- $O$-galloyl- $\beta$-D-glucose extracted from Galla chinensis binds to surface spike proteins of the virus [17, 29-32]. Various traditional herbal medicines from China under clinical trials for COVID-19 treatment are in the forms of: (1) injection, 
including Tan Re Qing, Re Du Ning, Shen Qi Fu Zheng, Shen Fu, Xi Yan Ping, and Xue Bi Jing, (2) capsule/granules such as Lian Hua Qing Wen, Gu Biao Jie Du Ling, Kang Bing Du, Ke Qing, Jing Yin and Tan Re Qing (3) oral liquids or syrup such as Shuang Huang Lian and Ke Su Ting [17]. Further, in silico analysis suggested that 26 Chinese herbals might be used during the course of treatment, including (1) full course herbs such as Forsythiae fructus, Liquorice, Mori cortex, Chrysanthemi flos, Farfarae flos, Lonicerae japonicae flos, Mori follum, Peucedani radix and Rhizoma fagopyri cymose, (2) at an early stage such as Tamaricis cacumen, Erigeron breviscapus and Radix bupleuri, (3) Middle stage such as Coptidis rhizome, Houttuyniae herba, Hoveniae dulcis semen and Inulae flos, (4) Middle and later stages such as Eriobotryae folium, Hedysarum multijugum maxim, Lepidii semen descurainiae semen, Ardisiae japonicae herba, Asteris radix et rhizome, Euphorbiae helioscopiae herba and Ginkgo semen, (5) Later stage such as Anemarrhenae rhizome and Epimrdii herba, and (6) for prevention such as Fortunes bossfern rhizome [19]. Liquorice root (Glycyrrhiza glabra) a native of Europe and Asia showed an anti-viral property towards SARS-CoVs that might be beneficial in this treatment because of the phytochemicals, including flavonoids (glycyrrhizin, liquiritigenin, and glabridin) and triterpenoids (glycyrrhizic acid, and glycyrrhetinic acid) [29]. Thailand's medical board has recommended licorice root for COVID19 treatment. More efforts are needed untill vaccine discovery takes place. Indian Ministry of Ayurveda, Yoga and Naturopathy, Un ani, Siddha, and Homoeopathy (AYUSH) also advise on the use of traditional medicine Arsenicum album although not supported by strong scientific evidence. Intake of anti-malarial drug AYUSH 64 (without side effects), sesame oil in the nose, and tulasi, ginger, guduchi (Tinospora cordifolia, and turmeric in the diet have been suggested. Ayurveda has worked towards enhancing immunity against a host of infections and homeopathy has been reported for treating cholera, Spanish influenza, yellow fever, and typhoid. It was also offered during the outbreak of Ebola in 2014 (Guinea, West Africa) due to a lack of vaccine or anti-virals (https://m.economictimes.com/ news).

\section{Conclusions and Future Perspectives}

Infectious diseases are caused by pathogens, which have resistance to antibiotics. Genomics plays a crucial role in diverse biotechnological applications including developing antipathogens [33-39]. The emergence of COVID-19 continues to plague the whole world. From about 212 Countries, over one million confirmed cases with a high mortality rate of $5.5 \%$ have been reported (https:// www.worldometers.info/coronavirus/). Lock-down for social distancing in mitigating COVID-19 has been found to be suitable for preventing pandemic scenario but it involves a heavy economic burden on the maintenance of essential services for health [40]. This strategy offers a short-term relief in delaying the transmissions. For a permanent remedy, investigations need to continue: (1) rapid and reliable testing kits, (2) short-term therapeutics and, and (3) finally vaccine for complete eradication. Genomic data are likely to provide insights into the evolutionary trends and their potential transmission among diverse hosts. Apart from various alternative approaches, traditional medicines known since long for curing such infections without side effects may prove beneficial.

Acknowledgements This work was supported by Brain Pool Grant (NRF-2020H1D3A2A01060467) by National Research Foundation of Korea (NRF) to work at Konkuk University (VCK). This work was also supported by KU Research Professor program of Konkuk University. This research was supported by Basic Science Research Program through the National Research Foundation of Korea (NRF) funded by the Ministry of Science, ICT and Future Planning (2019R1C1C11009766, 2020R1A4A2002854).

\section{References}

1. Bajaj A, Purohit HJ (2020) Understanding SARS-CoV-2: genetic diversity, transmission and cure in human. Indian J Microbiol. https://doi.org/10.1007/s12088-020-00869-4

2. Han Q, Lin Q, Jin S, You L (2020) Coronavirus 2019-nCoV: a brief perspective from the front line. J Infect 80:373-377. https:// doi.org/10.1016/j.jinf.2020.02.010

3. McKee DL, Sternberg A, Stange U, Laufer S, Naujokat C (2020) Candidate drugs against SARS-CoV-2 and COVID-19. Pharmacol Res 157:104859. https://doi.org/10.1016/j.phrs.2020.104859

4. Mani JS, Johnson JB, Steel JC, Broszczak DA, Neilsen PM, Walsh KB, Naiker M (2020) Natural product-derived phytochemicals as potential agent against coronaviruses. A review. Virus Res 284:197989. https://doi.org/10.1016/j.virusres.2020. 197989

5. Kumar R, Verma H, Singhvi N, Sood U, Gupta V, Singh M, Kumari R, Hira P, Nagar S, Talwar C, Nayyar N, Anand S, Rawat DC, Verma M, Negi RK, Singh Y, Lal R (2020) Comparative genomic analysis of rapidly evolving SARS CoV-2 viruses reveal mosaic pattern of phylogeographical distribution. BioRxiv. https://doi.org/10.1101/2020.03.25.006213

6. Sohrabi C, Alsafi Z, O'Neill N, Khan M, Kerwan A, Al-Jabir A, Iosifidis C, Agha R (2020) World health organization declares global emergency: a review of the 2019 novel coronavirus (COVID-19). Int J Surg 76:71-76. https://doi.org/10.1016/j.ijsu. 2020.02 .034

7. Sun J, He W-T, Wang L, Lai A, Ji X, Zhai X, Li G, Suchard MA, Tian J, Zhou J, Veit M, Su S (2020) COVID-19: epidemiology, evolution, and cross-disciplinary perspectives. Trends Mol Medic 26:483-495. https://doi.org/10.1016/j.molmed.2020.02.008

8. AminJafari A, Ghasemi S (2020) The possible of immunotherapy for COVID-19: a systematic review running title: immunotherapy for COVID-19. Int Immunopharm 83:106455. https://doi.org/10. 1016/j.intimp.2020.106455

9. Chang L, Yan Y, Wang L (2020) Coronavirus disease 2019: coronaviruses and blood safety. Transfus Med Rev. https://doi. org/10.1016/j.tmrv.2020.02.003 
10. Wang L-S, Wang Y-R, Ye D-W, Liu Q-Q (2020) Review of the 2019 novel coronavirus (COVID-19) based on current evidence. Int J Antimicrob Agents. https://doi.org/10.1016/j.ijantimicag. 2020.105948

11. Li X, Geng M, Peng Y, Meng L, Lu S (2020) Molecular immune pathogenesis and diagnosis of COVID-19. J Pharma Anal 10:102-108. https://doi.org/10.1016/j.jpha.2020.03.001

12. Shereen MA, Khan S, Kazmi A, Bashir N, Siddique R (2020) COVID-19 infection: origin, transmission, and characterization of human coronaviruses. J Adv Res 24:91-98. https://doi.org/10. 1016/j.jare.2020.03.005

13. Zhang L, Liu Y (2020) Potential interventions for novel coronavirus in China: a systemic review. J Med Virol 92:479-490. https://doi.org/10.1002/jmv.25707

14. Lu G, Wang Q, Gao GF (2015) Bat-to-human: spike features determining 'host jump' of coronaviruses SARS-CoV, MERS$\mathrm{CoV}$, and beyond. Trends Microbiol 23:8. https://doi.org/10. 1016/j.tim.2015.06.003

15. Dawood AA (2020) Mutated COVID-19, may foretells mankind in a great risk in the future. N Microb New Infect 35:100673. https://doi.org/10.1016/j.nmni.2020.100673

16. Singh R, Adhikari R (2020) Age-structured impact of social distancing on the COVID-19 epidemic in India. https://arxiv.org/ pdf/2003.12055.pdf. Accessed 6 June 2020

17. Yang Y, Islam MS, Wang J, Li Y, Chen X (2020) Traditional Chinese medicine in the treatment of patients infected with 2019-new coronavirus (SARS-CoV-2): a review and perspective. Int J Biol Sci 16:1708-1717. https://doi.org/10.7150/ijbs.45538

18. Sheahan TP, Sims AC, Graham RL, Menachery VD, Gralinski LE, Case JB, Leist SR, Pyrc K, Feng JY, Trantcheva I, Bannister R, Park Y, Babusis D, Clarke MO, Mackman RL, Spahn JE, Palmiotti CA, Siegel D, Ray AS, Cihlar T, Jordan R, Denison MR, Baric RS (2017) Broad-spectrum antiviral GS-5734 inhibits both epidemic and zoonotic coronaviruses. Sci Transl Med 9:eaal653. https://doi.org/10.1126/scitranslmed.aal3653

19. Zhang D-H, Wu K-L, Zhang X, Deng S-Q, Peng B (2020) In silico screening of Chinese herbal medicines with the potential to directly inhibit 2019 novel coronavirus. J Integ Med 18:152-158. https://doi.org/10.1016/j.joim.2020.02.005

20. Zhang R, Wang X, Ni L, Di X, Ma B, Niu S, Liu C, Reiter J (2020) COVID-19: melatonin as a potential adjuvant treatment. Life Sci 250:117583. https://doi.org/10.1016/j.lfs.2020.117583

21. Caly L, Druce JD, Catton MG, Jans DA, Wagstaff KM (2020) The FDA-approved drug ivermectin inhibits the replication of SARS-CoV-2 in vitro. Antiv Res 178:104787. https://doi.org/10. 1016/j.antiviral.2020.104787

22. Chavez S, Long B, Koyfman A, Liang SY (2020) Coronavirus disease (COVID-19): a primer for emergency physicians. Am J Emerg Med. https://doi.org/10.1016/j.ajem.2020.03.036

23. Devaux CA, Rolain J-M, Colson P, Raoult D (2020) New insights on the antiviral effects of chloroquine against coronavirus: what to expect for COVID-19? Int J Antimicrob Agents 55:105938. https://doi.org/10.1016/j.ijantimicag.2020.105938

24. Jean S-S, Lee P-I, Hsueh P-R (2020) Treatment options for COVID-19: the realty and challenges. J Microbiol Immunol Infect 53:436-443. https://doi.org/10.1016/j.jmii.2020.03.034

25. Lai C-C, Shih T-P, Ko W-C, Tang H-J, Hsueh P-R (2020) Severe acute respiratory syndrome coronavirus 2 (SARS-CoV-2) and coronavirus disease-2019 (COVID-19): the epidemic and the challenges. Int J Antimicrob Agents 55:105924. https://doi.org/ 10.1016/j.ijantimicag.2020.105924

26. Du CYQ, Zheng KYZ, Bi CW, Dong TTX, Lin H, Tsim KWK (2015) Yu Ping Feng San, an ancient Chinese herbal decoction, induces gene expression of anti-viral proteins and inhibits neuraminidase activity. Phytother Res 29:656-661. https://doi. org/10.1002/ptr.5290

27. Poon PMK, Wong CK, Fung KP, Fong CYS, Wong ELY, Lau JTF, Leung PC, Tsui SKW, Wan DCC, Waye MMY, Au SWN, Lau CBS, Lam CWK (2006) Immunomodulatory effects of a traditional Chinese medicine with potential antiviral activity: a self-control study. Am J Chin Med 34:13-21. https://doi.org/10. 1142/S0192415X0600359X

28. Ding Y, Zeng L, Li R, Chen Q, Zhou B, Chen Q, Cheng PL, Yutao W, Zheng J, Yang Z, Zhang F (2017) The Chinese prescription lianhuaqingwen capsule exerts anti-influenza activity through the inhibition of viral propagation and impacts immune function. BMC Complement Altern Med 17:130. https://doi.org/ 10.1186/s12906-017-1585-7

29. Pilcher H (2003) Liquorice may tackle SARS. Nature. https://doi. org/10.1038/news030609-16

30. Yu M-S, Lee J, Lee JM, Kim Y, Chin Y-W, Jee J-G, Keum Y-S, Jeong Y-J (2012) Identification of myricetin and scutellarein as novel chemical inhibitors of the SARS coronavirus helicase, nsP13. Bioorg Med Chem Lett 22:4049-4054. https://doi.org/10. 1016/j.bmcl.2012.04.081

31. Kim DE, Min JS, Jang MS, Lee JY, Shin YS, Park CM, Song JH, Kim HR, Kim S, Jin Y-H, Know S (2019) Natural bis-benzylisoquinoline alkaloids-tetrandrine, fangchinoline, and cepharanthine, inhibit human coronavirus OC43 infection of MRC-5 human lung cells. Biomolecules 9:696. https://doi.org/10.3390/ biom9110696

32. Jo S, Kim S, Shin DH, Kim M-S (2020) Inhibition of SARS-CoV $3 \mathrm{CL}$ protease by flavonoids. J Enzyme Inhib Med Chem 35:145-151. https://doi.org/10.1080/14756366.2019.1690480

33. Kalia VC (2013) Quorum sensing inhibitors: an overview. Biotechnol Adv 31:224-245. https://doi.org/10.1016/j.bio techadv.2012.10.004

34. Kalia VC, Patel SKS, Kang YC, Lee J-K (2019) Quorum sensing inhibitors as antipathogens: biotechnological applications. Biotechnol Adv 37:68-90. https://doi.org/10.1016/j.biotechadv. 2018.11.006

35. Kalia VC, Purohit HJ (2011) Quenching the quorum sensing system: potential antibacterial drug targets. Crit Rev Microbiol 37:121-140. https://doi.org/10.3109/1040841X.2010.532479

36. Kalia VC, Raju SC, Purohit HJ (2011) Genomic analysis reveals versatile organisms for quorum quenching enzymes: acyl-homoserine lactone-acylase and-lactonase. Open Microbiol J 5:1-11. https://doi.org/10.2174/1874285801105010001

37. Kalia VC, Wood TK, Kumar P (2014) Evolution of resistance to quorum-sensing inhibitors. Microb Ecol 68:13-23. https://doi. org/10.1007/s00248-013-0316-y

38. Kumar P, Patel SKS, Lee JK, Kalia VC (2013) Extending the limits of Bacillus for novel biotechnological applications. Biotechnol Adv 31:1543-1561. https://doi.org/10.1016/j.bio techadv.2013.08.007

39. Parasuraman P, Devadatha B, Sarma VV, Ranganathan S, Ampasala DR, Reddy D, Kumavath R, Kim I-W, Patel SKS, Kalia VC, Lee J-K, Siddhardha B (2020) Inhibition of microbial quorum sensing mediated virulence factors by Pestalotiopsis sydowiana. J Microbiol Biotechnol 30:571-582. https://doi.org/ 10.4014/jmb.1907.07030

40. Ha K-M (2020) A lesson learned from the outbreak of COVID-19 in Korea. Indian J Microbiol. https://doi.org/10.1007/s12088-02000882-7

Publisher's Note Springer Nature remains neutral with regard to jurisdictional claims in published maps and institutional affiliations. 